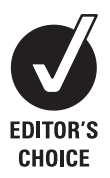

See Editorial, p 944

- Additional tables are published online only at http:// thorax.bmi.com/content/vol63/ issue 11

${ }^{1}$ Epidemiology \& Public Health, University of Nottingham, UK;

${ }^{2}$ Epidemiology \& Population

Health, London School of

Hygiene \& Tropical Medicine, UK

Correspondence to:

Dr L J Tata, Division of

Epidemiology \& Public Health,

Clinical Sciences Building, City

Hospital, Hucknall Road,

Nottingham NG5 1PB, UK;

laila.tata@nottingham.ac.uk

Received 28 February 2008

Accepted 6 July 2008

Published Online First

4 August 2008

\title{
Effect of maternal asthma, exacerbations and asthma medication use on congenital malformations in offspring: a UK population-based study
}

\author{
L J Tata, ${ }^{1}$ S A Lewis, ${ }^{1}$ T M McKeever, ${ }^{1}$ C J P Smith, ${ }^{1}$ P Doyle, ${ }^{2}$ L Smeeth, ${ }^{2}$ J E Gibson, \\ R B Hubbard ${ }^{1}$
}

\begin{abstract}
Background: Clinical advice to pregnant women with asthma is to maintain optimal therapeutic management; however, potential adverse effects of asthma treatments on fetal development remain uncertain. A study was undertaken to assess the association between maternal asthma and gestational exposure to asthma medications with risk of congenital malformation in offspring.

Methods: A matched case-control study was performed using The Health Improvement Network primary care database. Children with malformations were matched to control children on birth year, general practice and singleton or twin delivery.
\end{abstract}

Results: 5124 cases of liveborn children with major congenital malformations and 30053 controls were included in the study. The risk of any malformation in children born to women with asthma was marginally higher than that in children born to women without asthma (adjusted OR 1.10, 95\% Cl 1.01 to 1.20). However, no association was present in children born to mothers receiving asthma treatment in the year before or during pregnancy (OR 1.06, 95\% Cl 0.94 to 1.20). In assessing teratogenicity of medications, no increased risk of malformation was found with gestational exposures to short- or long-acting $\beta$ agonists, inhaled corticosteroids, oral corticosteroids, other bronchodilators or cromones. These findings were similar for each of 11 system-specific malformation groups, except for an increase in musculoskeletal system malformation associated with cromone exposure.

Conclusions: Gestational exposure to commonly used asthma medications was found to be safe overall, although a moderate teratogenic risk of cromones cannot be excluded. There was some evidence of a small increased risk of congenital malformation in children born to women with asthma, but this was not explained by gestational exposure to asthma drugs.

Although clinical advice to pregnant women with asthma is to maintain optimal therapeutic management, the potential adverse effects of their condition and indicated treatments on fetal development remain uncertain. Current figures from the USA show that at least $8 \%$ of women have active asthma in pregnancy and $14 \%$ were diagnosed previously, ${ }^{1}$ placing asthma medications in the second most commonly used drug class in pregnancy. $^{2}$

Congenital malformations are the leading cause of infant mortality in the USA ${ }^{3}$ and the second leading cause in the UK, ${ }^{4}$ but currently published asthma management guidelines in these countries ${ }^{5}$ include only five epidemiological studies assessing teratogenic effects of asthma treatments against unexposed comparisons. ${ }^{7-11}$ None of these studies reported increased risks of congenital malformation, but the available statistical power was very limited. ${ }^{12}$ More recently, larger studies have been conducted in Hungary $^{13}$ and Sweden. ${ }^{14}$ The first ${ }^{13}$ found that mothers of children with malformations had a $20 \%$ greater risk of having asthma compared with mothers of children without malformations; however, asthma drug use was self-reported after a malformation outcome was known and the proportions of drug-exposed women were extremely small. ${ }^{15}{ }^{16}$ In Sweden ${ }^{14}$ a small (9\%) but statistically significant increase in congenital malformation was found in children of women reporting use of antiasthmatic drugs in pregnancy compared with nonusers, although no consistent pattern of malformations was identified and the authors concluded that further large studies were needed. There remain no large analyses of current UK prescribing of asthma medications in women with congenital malformations in offspring.

There is a clear need for further surveillance data $^{17}$ on the safety of asthma medications during pregnancy, particularly since pregnant women are likely to be excluded from randomised trials. We therefore undertook the first large UK populationbased study assessing the risk of maternal asthma and exposure to current asthma treatments during pregnancy on overall and system-specific major congenital malformations in offspring.

\section{METHODS}

\section{Dataset and study population}

The Health Improvement Network (THIN) is a computerised primary care database of anonymised patient records based in the UK, with a high standard of validated recording of diagnoses, medical events and prescriptions. ${ }^{18}$ Rates of consultation, drug prescription and pregnancy are similar to national data sources. ${ }^{19}{ }^{20}$ For this study, longitudinal THIN records were available for 255 general practices across England and Wales.

Using prospectively collected data for women of childbearing age (15-50 years), we linked birthrelated codes in their record to live births of children registered in the same household at the time of delivery. Children were born between January 1988 and November 2004. We obtained 180064 mother-child pairs with gestational data, within which we identified all major congenital malformations in the children and categorised 
them using the European Surveillance of Congenital Malformations (EUROCAT) classification ${ }^{21}$ which separates malformations into 11 system-specific groups. We defined cases as liveborn children with one or more major malformation and for each case we identified up to six liveborn control children matched by year of birth, general practice and singleton or twin delivery. To test the validity of congenital malformation diagnoses we compared the prevalence of congenital malformations in our overall study population with that of the UK-based EUROCAT registries. We also compared the distribution of maternal age in trisomy 21 cases and controls to confirm the expected higher maternal age distribution in cases.

\section{Statistical analyses}

The unit of analysis was the child. Conditional logistic regression was used to assess the association of any major congenital malformation or any system-specific major congenital malformation with maternal asthma and maternal asthma drug treatment. Maternal asthma was defined on the basis of recorded diagnoses at any time before the delivery of the child or prescriptions for asthma medications issued at the general practice during pregnancy or in the year before pregnancy. Since some of the mothers had an asthma diagnosis but no asthma medication use and other mothers used asthma medications but had no diagnosis, we assessed the separate risk of congenital malformations in four groups: (1) children born to mothers with an all-inclusive definition of maternal asthma which was either diagnosed asthma or exposure to asthma maintenance medication; (2) children born to mothers with diagnosed asthma but no exposure to asthma maintenance medication; (3) children born to mothers with exposure to asthma maintenance medication but no asthma diagnosis; and (4) children born to mothers with both a diagnosis of asthma and exposure to asthma maintenance medication.

Asthma maintenance medications were classified as shortacting $\beta$ agonists (fenoterol, salbutamol, terbutaline or bambuterol), inhaled corticosteroids (beclometasone, budesonide, fluticasone or mometasone), long-acting $\beta$ agonists (formoterol or salmeterol), other bronchodilators (aminophylline, theophylline, ephedrine, orciprenaline, tiotropium or ipratropium) or other anti-inflammatory medications (sodium cromoglicate, nedocromil, montelukast or zafirlukast). In all children whose mothers had a record of asthma, we additionally assessed the association of congenital malformation with clinically reported maternal asthma exacerbations during pregnancy. An exacerbation was defined as a clinical code for an exacerbation, acute asthma attack or emergency hospital admission for asthma, or an oral corticosteroid prescription.

To test the teratogenicity of specific asthma drug groups we examined the risk of congenital malformation associated with gestational exposures to the asthma maintenance medications classified above as well as oral corticosteroids (betamethasone, cortisone acetate, deflazacort, dexamethasone, hydrocortisone, prednisolone or triamcinolone). Prescriptions issued by the general practice during the woman's pregnancy were used for gestational exposures. All prescriptions are issued electronically at the general practice by physicians or certified nurse practitioners, with the date of prescription and specific details of the drug name, formulation, dose and duration retained in the woman's electronic general practice record. For this study, gestational drug exposure was considered as having one or more prescriptions for any specific drugs within the drug classes listed above. We also conducted secondary analyses restricted to drug exposures in the first trimester of pregnancy only.
The models were adjusted for exact maternal age as a continuous variable and the effects of other potential confounding factors (maternal smoking, body mass index before pregnancy, household socioeconomic status measured by Townsend deprivation index ${ }^{22}$ quintile, child sex, delivery before, at or after term) were assessed. Since some children in the study were born to the same woman (ie, some women contributed more than one pregnancy during the study period), we allowed for potential clustering by woman using robust standard errors. ${ }^{23}$ Missing values for covariates were fitted as a separate category and all models were re-fitted using cases and controls with complete data.

\section{Statistical power and multiple testing}

Our study population size gave us over $95 \%$ power to detect an odds ratio (OR) of $\geqslant 1.2$ for any major malformation associated with maternal asthma and over $90 \%$ power to detect an OR of 2.0 for most system-specific major malformations. To assess common gestational drug exposures (eg, short-acting $\beta$ agonists), we had $90 \%$ power to detect an OR of 1.2 and to assess less common exposures (eg, oral corticosteroids) we had $95 \%$ power to detect an OR of 2.0. A significance level of 0.05 was used for these power calculations.

For our drug safety analyses, a large number of multiple comparisons were carried out in the gestational drug exposure assessment of six different drug families with malformations overall and with 11 system-specific groups. Some ORs will therefore be statistically significant at the 5\% level by chance alone, while only ORs with highly significant $p$ values $(e g, p<0.01)$ should be considered as those more likely not to be due to chance. We present $95 \%$ confidence intervals for ORs but, in light of these multiple comparisons, we also provided exact $p$ values to allow comprehensive interpretation of findings.

\section{RESULTS}

\section{Validation of study population}

The prevalence of a major congenital malformation in our population was 289 per 10000 live births which was similar to the national prevalence for EUROCAT registries in the UK (238 per 10000 births including live births, stillbirths, fetal deaths and pregnancy terminations). ${ }^{24}$ This equated to 5200 children with major congenital malformations in our population of 180064 children, and we successfully matched 5124 of these cases to 30053 control children without malformation. These data confirmed an association between trisomy 21 risk and increasing maternal age (OR 1.65, 95\% confidence interval (CI) 1.35 to 2.00 for each 5 -year increase in maternal age).

\section{Description of the case-control dataset}

For all 5124 cases, maternal age at birth was similar to that for the 30053 matched controls (table 1). Compared with mothers of controls, mothers of cases were more likely to be obese before the pregnancy (OR 1.16, 95\% CI 1.03 to 1.31 ) or to be underweight before the pregnancy (OR 1.19, 95\% CI 1.00 to 1.42). Cases and controls had a similar proportion of mothers who were current smokers before the pregnancy (OR 1.00, 95\% CI 0.92 to 1.08) and had the same distribution across levels of household socioeconomic status. More cases than controls were delivered before term (OR 2.62, 95\% CI 2.21 to 3.11), and cases were more likely to be male (OR $1.32,95 \%$ CI 1.25 to 1.40 ). 
Table 1 Description of cases and controls

\begin{tabular}{|c|c|c|c|}
\hline & Cases $(n=5124)$ & $\begin{array}{l}\text { Controls } \\
(\mathrm{n}=\mathbf{3 0 0 5 3 )}\end{array}$ & \\
\hline & n $(\%)^{*}$ & n (\%)* & $(95 \% \mathrm{Cl})$ \\
\hline Median (IOR) maternal age at delivery (years) & $29.6(25.5-33.2)$ & $29.4(25.5-33.1)$ & $1.01(1.00$ to 1.01$)$ \\
\hline \multicolumn{4}{|l|}{ Maternal body mass index $\left(\mathrm{kg} / \mathrm{m}^{2}\right)$} \\
\hline Underweight $(<18.5)$ & $163(3.2)$ & $827(2.8)$ & $1.19(1.00$ to 1.42$)$ \\
\hline Normal (18.5-24.9) & $2031(39.6)$ & $12280(40.9)$ & Reference \\
\hline Overweight (25-29.9) & $709(13.8)$ & $4131(13.7)$ & $1.04(0.95$ to 1.14$)$ \\
\hline Obese $(\geqslant 30)$ & $385(7.5)$ & $1997(6.6)$ & $1.16(1.03$ to 1.31$)$ \\
\hline Missing & $1836(35.8)$ & $10818(36.0)$ & $1.01(0.93$ to 1.10$)$ \\
\hline \multicolumn{4}{|l|}{ Maternal smoking status } \\
\hline Non-smoker & $2590(50.5)$ & $15046(50.1)$ & Reference \\
\hline Ex-smoker & $269(5.2)$ & $1473(4.9)$ & $1.06(0.92$ to 1.22$)$ \\
\hline Current smoker & $1136(22.2)$ & $6637(22.1)$ & $1.00(0.92$ to 1.08$)$ \\
\hline Missing & $1129(22.0)$ & $6897(23.0)$ & $0.92(0.84$ to 1.01$)$ \\
\hline \multicolumn{4}{|l|}{ Household Townsend score quintile } \\
\hline 1 (least deprivation) & $826(16.1)$ & $4976(16.6)$ & Reference \\
\hline 2 & $592(11.6)$ & $3499(11.6)$ & $1.02(0.90$ to 1.15$)$ \\
\hline 3 & $586(11.4)$ & $3387(11.3)$ & $1.05(0.93$ to 1.19$)$ \\
\hline 4 & $506(9.9)$ & $2833(9.4)$ & $1.08(0.95$ to 1.24$)$ \\
\hline 5 (most deprivation) & $400(7.8)$ & $2337(7.8)$ & $1.04(0.90$ to 1.21$)$ \\
\hline Missing & $2214(43.2)$ & $13021(43.3)$ & $0.87(0.67$ to 1.12$)$ \\
\hline \multicolumn{4}{|l|}{ Term of pregnancy } \\
\hline Preterm & $366(7.1)$ & $858(2.9)$ & $2.62(2.21$ to 3.11$)$ \\
\hline Term & $705(13.8)$ & $4503(15.0)$ & Reference \\
\hline Post-term & $8(<0.5)$ & $39(<0.5)$ & $1.29(0.54$ to 3.05$)$ \\
\hline Missing & $4045(78.9)$ & $24653(82.1)$ & $1.01(0.88$ to 1.16$)$ \\
\hline \multicolumn{4}{|l|}{ Sex of child } \\
\hline Female & $2172(42.4)$ & $14829(49.4)$ & Reference \\
\hline Male & $2952(57.6)$ & $15224(50.7)$ & $1.32(1.25$ to 1.40$)$ \\
\hline \multicolumn{4}{|l|}{ Singleton or multiple delivery } \\
\hline Singleton & 4996 (97.5) & $29655(98.7)$ & Matching variable \\
\hline Twin & $128(2.5)$ & $398(1.3)$ & \\
\hline \multicolumn{4}{|l|}{ Year of birth } \\
\hline $1988-9$ & $196(3.8)$ & $1104(3.7)$ & Matching variable \\
\hline $1990-4$ & $1567(30.6)$ & $9192(30.6)$ & \\
\hline $1995-9$ & $1768(34.5)$ & $10389(34.6)$ & \\
\hline $2000-4$ & $1593(31.1)$ & $9368(31.2)$ & \\
\hline
\end{tabular}

*Proportion of cases or controls. IQR, interquartile range.

\section{Associations of any malformation with maternal asthma}

The proportion of mothers with either a diagnosis of asthma, exposure to asthma maintenance medication before the delivery of the child, or both (our all-inclusive definition of asthma) was $14 \%$ for cases with congenital malformation and 13\% for matched control children (table 2). Cases were marginally more likely than controls to have mothers with asthma in each of the four defined groups, ranging from a $6-17 \%$ relative increase. However, it was only in the all-inclusive definition of maternal asthma with the largest number of exposed cases that a statistically significant association at the $5 \%$ level was found. The highest relative increase in congenital malformation was in children born to mothers with diagnosed asthma but no asthma medication use, whereas the smallest was in children born to mothers with diagnosed asthma who were using asthma medications. Cases were no more likely than controls to have a mother with clinically reported asthma exacerbations in pregnancy (OR $1.09,95 \%$ CI 0.65 to $1.82 ; \mathrm{p}=0.754$ ).

In our assessment of gestational exposure to asthma medications, cases were as likely as controls to be exposed to each of the six asthma drug categories (table 2). Most ORs for drug exposure were close to unity with the exception of exposure to other anti-inflammatory medications (OR 2.02, $95 \%$ CI 0.96 to $4.28 ; p=0.065$ ). This OR was based on only a small number of gestational exposures and all nine exposed cases were to cromones while, in controls, 26 were exposed to cromones and 1 was exposed to montelukast. We repeated all analyses using only first trimester gestational drug exposures and the results were similar to the overall analyses: short-acting $\beta$ agonists (OR 1.01, 95\% CI 0.86 to $1.18, p=0.941$ ), inhaled corticosteroids (OR 1.06, 95\% CI 0.86 to 1.31, $\mathrm{p}=0.603$ ), longacting $\beta$ agonists (OR 1.09, 95\% CI 0.62 to $1.90, p=0.770$ ), oral corticosteroids (OR 1.16, 95\% CI 0.71 to $1.89, \mathrm{p}=0.550$ ), other bronchodilators (OR 1.05, 95\% CI 0.44 to $2.51, \mathrm{p}=0.905$ ), other anti-inflammatory medications (OR 2.00, $95 \%$ CI 0.72 to 5.52 , $\mathrm{p}=0.183)$.

In multivariate analyses of all defined maternal asthma groups and gestational drug exposures, none of the potential confounding factors (maternal smoking, body mass index before pregnancy, household socioeconomic status, child sex and term of delivery) changed our risk estimates by more than 10\% (eg, fully adjusted OR $1.05,95 \%$ CI 0.93 to 1.19 for maternal diagnosis and asthma medication before delivery), so all ORs presented are only adjusted for maternal age. The effect 
Table 2 Risk of any major congenital malformation in children born to mothers with asthma

\begin{tabular}{|c|c|c|c|c|}
\hline & $\begin{array}{l}\text { Cases } \\
(\mathrm{n}=5124)\end{array}$ & $\begin{array}{l}\text { Controls } \\
(\mathrm{n}=30053)\end{array}$ & & \\
\hline & $\mathbf{n}(\%) \dagger$ & $\mathbf{n}(\%) \dagger$ & Adjusted $\mathrm{OR} \div(95 \% \mathrm{Cl})$ & p Value \\
\hline \multicolumn{5}{|l|}{ Maternal asthma status } \\
\hline $\begin{array}{l}\text { No asthma diagnosis or medications before } \\
\text { delivery }\end{array}$ & $4420(86.3)$ & $26235(87.3)$ & Reference & \\
\hline $\begin{array}{l}\text { Asthma diagnosis or medication§ before } \\
\text { delivery }\end{array}$ & $704(13.7)$ & $3818(12.7)$ & $1.10(1.01$ to 1.20$)$ & 0.032 \\
\hline Diagnosis with no medication before delivery & $171(3.3)$ & $881(2.9)$ & $1.17(0.99$ to 1.39$)$ & 0.071 \\
\hline $\begin{array}{l}\text { Asthma medication§ but no diagnosis before } \\
\text { delivery }\end{array}$ & $183(3.6)$ & $968(3.2)$ & $1.13(0.96$ to 1.33$)$ & 0.132 \\
\hline $\begin{array}{l}\text { Diagnosis and asthma medication§ before } \\
\text { delivery }\end{array}$ & $350(6.8)$ & $1969(6.6)$ & $1.06(0.94$ to 1.20$)$ & 0.329 \\
\hline$\geqslant 1$ asthma exacerbation during pregnancy & $18(<0.5)$ & $94(<0.5)$ & $1.09(0.65$ to 1.82$)$ & 0.754 \\
\hline \multicolumn{5}{|l|}{$\geqslant 1$ medication exposure during pregnancy* } \\
\hline Any asthma medication & $410(8.0)$ & $2240(7.5)$ & $1.05(0.94$ to 1.18$)$ & 0.367 \\
\hline Short-acting $\beta$ agonist & $375(7.3)$ & $2085(6.9)$ & $1.06(0.94$ to 1.19$)$ & 0.336 \\
\hline Inhaled corticosteroid & $220(4.3)$ & $1209(4.0)$ & $1.07(0.92$ to 1.24$)$ & 0.407 \\
\hline Long-acting $\beta$ agonist & $25(<0.5)$ & $131(<0.5)$ & $1.12(0.72$ to 1.75$)$ & 0.614 \\
\hline Oral corticosteroid & $46(0.9)$ & $216(0.7)$ & $1.23(0.89$ to 1.69$)$ & 0.201 \\
\hline Other bronchodilator medication & $13(<0.5)$ & $72(<0.5)$ & $1.05(0.59$ to 1.87$)$ & 0.872 \\
\hline Other anti-inflammatory medication** & $9(<0.5)$ & $27(<0.5)$ & $2.02(0.96$ to 4.28$)$ & 0.065 \\
\hline
\end{tabular}

estimates were also similar when we repeated each analysis using only those with full data for covariates (eg, fully adjusted OR $1.07,95 \%$ CI 0.88 to 1.29 for maternal diagnosis and asthma medication before delivery for 1730 cases and 10138 controls with full covariate data).

\section{Associations of system-specific malformation with maternal asthma}

When we carried out analyses of maternal asthma (all-inclusive definition and grouped by diagnoses/medication use) and clinically reported exacerbations in pregnancy for the 11 major system-specific malformation groups, we found similar results to those for any major congenital malformation (full data available in additional tables published online only). All ORs were $<2.00$ and had $p$ values $>0.01$, with the exception of an association of musculoskeletal system malformations with the all-inclusive definition of maternal asthma (OR 1.25, 95\% CI 1.06 to $1.47 ; p=0.009$ ) and with asthma medication but no diagnosis before delivery (OR 1.46, 95\% CI 1.11 to 1.93 ; $\mathrm{p}=0.007)$. The associations of system-specific malformations in children born to mothers with diagnosed asthma who were using asthma medications are presented in table 3.

For gestational exposure to asthma medications (table 3), there was no evidence of an increased risk of system-specific malformations (ORs $<2.00$ or $\mathrm{p}$ values $>0.01$ ), apart from a large relative increase in musculoskeletal system malformations in children born to mothers with gestational exposure to cromones (OR 9.38, 95\% CI 2.31 to 38.10; $p=0.002$ ) compared with no exposure; however, this was based on only five exposed cases (full data available in additional tables published in online supplement). The specific malformations in these five cases were congenital hip dislocation $(n=3)$, congenital shortening of leg $(n=1)$ and imperfect fusion of the skull $(n=1)$.
Malformations in the remaining four cases with gestational exposure to cromones also showed no consistent pattern; one child had major congenital malformation of the lacrimal passages, one had cleft palate with bilateral cleft lip, one had Down's syndrome with ventricular septal defect and one had hypospadias.

\section{DISCUSSION \\ Principal findings}

The results of this first UK general population-based study show that the risk of major congenital malformation in children born to mothers with asthma is similar to that in children born to mothers without asthma. Cases were only marginally more likely than controls to have mothers with asthma in each of our defined groups of maternal asthma, and there was only a statistically significant association at the $5 \%$ level when the number of maternal asthma-exposed cases was highest and hence statistical power greatest. Since the effect seen here was small (10\% increase) and was not present for cases whose mothers were treated for asthma, this pattern of results overall does not support an increased risk of malformation in children born to women with asthma.

Gestational exposure to asthma therapies did not appear to increase the risk of any major congenital malformation or system-specific malformation, providing evidence of their general safety in pregnancy. The only exposure of possible concern was a marked increase in the risk of musculoskeletal malformations associated with cromone anti-inflammatory medications based on a small number of exposed cases.

\section{Strengths and limitations}

We have conducted the largest comprehensive multivariate analysis in the UK population to assess the potential teratogenic effects of current asthma medications associated with overall 
Table 3 Risk of major system-specific congenital malformation in children born to mothers with actively treated diagnosed asthma and in children with gestational exposure to asthma medication

\begin{tabular}{|c|c|c|c|c|}
\hline & Cases & Controls & & \\
\hline & $\mathbf{n}(\%) \dagger$ & n $(\%) \dagger$ & Adjusted $\mathrm{OR} \div(95 \% \mathrm{CI})$ & p Value \\
\hline \multicolumn{5}{|c|}{$\begin{array}{l}\text { Maternal asthma (diagnosis and medication } \\
\text { before delivery) }\end{array}$} \\
\hline Any congenital malformation§ & $5124(6.8)$ & $30053(6.6)$ & $1.06(0.94$ to 1.20$)$ & 0.329 \\
\hline \multicolumn{5}{|c|}{ Any system-specific malformation } \\
\hline Nervous system & $237(7.2)$ & $1377(6.8)$ & $1.08(0.63$ to 1.86$)$ & 0.783 \\
\hline Eye, ear, face, neck & $293(5.8)$ & $1718(5.8)$ & $1.01(0.58$ to 1.76$)$ & 0.972 \\
\hline Circulatory system & $1256(7.6)$ & $7356(6.6)$ & 1.18 (0.94 to 1.49$)$ & 0.163 \\
\hline Respiratory system & $46(10.9)$ & $265(7.2)$ & $1.71(0.50$ to 5.78$)$ & 0.390 \\
\hline Cleft lip and/or palate & $255(7.1)$ & $1513(6.8)$ & $1.05(0.62$ to 1.77$)$ & 0.852 \\
\hline Digestive system & $166(7.2)$ & $974(7.0)$ & $1.03(0.53$ to 2.00$)$ & 0.932 \\
\hline Genital organs & $913(6.2)$ & $5345(6.3)$ & $0.98(0.73$ to 1.31$)$ & 0.874 \\
\hline Urinary system & $313(6.7)$ & $1850(6.6)$ & $1.03(0.63$ to 1.68$)$ & 0.921 \\
\hline Musculoskeletal system & $1431(7.3)$ & $8372(6.6)$ & $1.14(0.91$ to 1.43$)$ & 0.241 \\
\hline "Other" & $407(7.1)$ & $2400(6.5)$ & $1.15(0.75$ to 1.77$)$ & 0.518 \\
\hline Chromosomal abnormality & $260(2.3)$ & $1519(5.7)$ & $0.43(0.18$ to 1.02$)$ & 0.054 \\
\hline \multicolumn{5}{|c|}{$\begin{array}{l}\geqslant 1 \text { Asthma medication exposure during } \\
\text { pregnancy* }\end{array}$} \\
\hline Any congenital malformation§ & $5124(8.0)$ & $30053(7.5)$ & $1.05(0.94$ to 1.18$)$ & 0.367 \\
\hline \multicolumn{5}{|c|}{ Any system-specific malformation } \\
\hline Nervous system & $237(6.8)$ & $1377(7.2)$ & $0.93(0.55$ to 1.57$)$ & 0.781 \\
\hline Eye, ear, face, neck & $293(5.8)$ & $1718(7.1)$ & $0.81(0.48$ to 1.38$)$ & 0.439 \\
\hline Circulatory system & $1256(9.0)$ & $7356(7.3)$ & $1.27(1.02$ to 1.58$)$ & 0.032 \\
\hline Respiratory system & $46(13.0)$ & $265(7.9)$ & $1.92(0.65$ to 5.65$)$ & 0.236 \\
\hline Cleft lip and/or palate & $255(6.3)$ & $1513(8.3)$ & $0.73(0.43$ to 1.24$)$ & 0.246 \\
\hline Digestive system & $166(12.0)$ & $974(7.9)$ & $1.65(0.99$ to 2.74$)$ & 0.053 \\
\hline Genital organs & $913(7.6)$ & $5345(7.6)$ & $0.98(0.74$ to 1.28$)$ & 0.865 \\
\hline Urinary system & $313(8.0)$ & $1850(7.1)$ & $1.13(0.72$ to 1.77$)$ & 0.594 \\
\hline Musculoskeletal system & $1431(8.7)$ & $8372(7.6)$ & 1.16 (0.95 to 1.43$)$ & 0.143 \\
\hline "Other" & $407(7.4)$ & $2400(7.2)$ & 1.04 (0.69 to 1.58$)$ & 0.842 \\
\hline Chromosomal abnormality & $260(3.5)$ & $1519(7.0)$ & $0.45(0.22$ to 0.95$)$ & 0.035 \\
\hline \multicolumn{5}{|c|}{$\begin{array}{l}{ }^{*} \text { Any short-acting } \beta \text { agonists, inhaled corticosteroids, long-acting } \beta \text { agonists, other bronchodilators or other anti-inflammatory } \\
\text { medications (see tables published in online supplement for full analyses of individual gestational drug exposures). } \\
\text { †First section of table: Proportion of cases or controls whose mothers have an asthma diagnosis and medication before delivery. } \\
\text { Second section of table: Proportion of cases or controls exposed to one or more asthma medications during pregnancy. } \\
\text { †Odds ratios (95\% confidence intervals) adjusted for maternal age at birth of case or control child; maternal smoking status, body } \\
\text { mass index, socioeconomic status, sex of the child, gestation of pregnancy had no confounding effects. } \\
\S \text { Children with more than one malformation are counted only once in "any congenital malformation" total. } \\
\text { ๆChildren with more than one malformation in the same system-specific group are counted only once in each system-specific } \\
\text { malformation total. }\end{array}$} \\
\hline
\end{tabular}

and system-specific malformations. Our data were obtained from a national database of prospectively collected clinical records, thus excluding the possibility of recall bias in our exposures of maternal asthma and prescription medication use. Although THIN is a relatively new database, respiratory diagnoses and perinatal outcomes in the General Practice Research Database (GPRD), a similar database from which over half of THIN practices originate, have shown high validity and completeness. ${ }^{25}{ }^{26}$ A recent study also demonstrated that nonGPRD practices in THIN have the same high standard of data validity as GPRD practices. ${ }^{18}$

In assessing the external validity of our study, our populationbased prevalence of current asthma in women of child-bearing age is similar to both $\mathrm{UK}^{27}$ and US ${ }^{1}$ national figures. Since congenital malformations have not previously been investigated in THIN, we compared prevalence figures for any malformation and system-specific malformations in our study population with those from UK registries of EUROCAT over the same time period and found these to be similar. ${ }^{24}$ We also demonstrated the expected increase in risk of having a child with trisomy 21 for women of older maternal age in our data.
Our study power enabled us to assess the effects of potential confounding factors in multivariate analyses for each drug exposure with overall and system-specific malformation. We recognise the presence of some missing data for maternal smoking (23\%), body mass index (36\%) and socioeconomic status (43\%). At the time of data collection, THIN were only able to provide Townsend deprivation index-our measure of socioeconomic status-for 176 of the 255 general practices because the process of integrating this variable into the database for research purposes was in development. Although the proportion of missing data for each covariate was the same between cases and controls, we repeated analyses using only those with full data for covariates and obtained similar effect sizes to the overall analyses.

All studies using repeated statistical analyses to assess several drug exposures in one population are at risk of revealing spurious associations because high numbers of multiple comparison tests result in statistically significant $p$ values by chance alone, and it is important to consider whether these associations are causal. Studies of drug safety typically use a $5 \%$ level for statistical significance $(p<0.05)$ but, in consideration of 
Table 4 Publications reporting statistical analyses of the risk of congenital malformation associated with gestational exposure to asthma medication compared with no exposure

\begin{tabular}{|c|c|c|c|c|}
\hline Reference & Gestational exposure & $\begin{array}{l}\text { Children with congenital malformation } \\
\text { (number born to women with asthma/ } \\
\text { without asthma) }\end{array}$ & Multivariate analysis & Increased risk $\dagger$ \\
\hline Schatz et al $l^{7}$ & Inhaled bronchodilators & $<50 /<50^{*}$ & Yes & No \\
\hline Stenius-Aarniala et $a l^{11}$ & Theophylline & $10 / 2$ & No & No \\
\hline Schatz et $a l^{8}$ & $\begin{array}{l}\beta \text { agonists, theophylline, cromolyn, CS, } \\
\text { antihistamines, decongestants }\end{array}$ & $<50 /<50^{*}$ & No & No \\
\hline Alexandre et $a l^{10}$ & $\beta$ agonists, CS & $88 / 981$ & Yes & No \\
\hline Schatz et $a l^{39}$ & $\begin{array}{l}\beta \text { agonist, ICS, OCS, theophylline, } \\
\text { cromoglicates }\end{array}$ & $42 / 0^{*}$ & No & No \\
\hline Tamasi et $a l^{13}$ & $\begin{array}{l}\text { SABA, ICS, LABA, OCS, xanthines, sodium } \\
\text { cromoglicate }\end{array}$ & $511 / 22322+$ & No & $\begin{array}{l}\text { Yes with fenoterol, no with } \\
\text { other medications }\end{array}$ \\
\hline Blais et $\left.a\right|^{38}$ & ICS & $418 / 0$ & Yes & No \\
\hline Bakhireva et $a l^{37}$ & $\beta$ agonists, leucotriene receptor antagonists & $9 / 1$ & Yes & Yes \\
\hline Kallen et $a l^{14}$ & $\begin{array}{l}\text { SABA, ICS, LABA, other bronchodilators } \uparrow, \\
\text { other anti-inflammatories }\end{array}$ & $1263 / 41223$ & Yes & Yes§ \\
\hline Current publication & $\begin{array}{l}\text { SABA, ICS, LABA, OCS, other } \\
\text { bronchodilators }{ }^{*} \text {, other anti-inflammatories** }\end{array}$ & $704 / 4420$ & Yes & No \\
\hline
\end{tabular}

*Numbers estimated from published percentages (no numbers presented in paper).

$\uparrow$ Statistically significant increase in malformation with gestational drug exposure (at $5 \%$ level).

\$.Mostly major malformations but included some minor (clubfoot, pyloric stenosis, undescended testis).

$\S$ Although system-specific malformations had no generally consistent pattern and statistically significant associations found only for severe cardiac defects, orofacial clefts, anal atresia.

-Other bronchodilators: aminophylline, theophylline, ephedrine, orciprenaline, tiotropium or ipratropium.

**0ther anti-inflammatories: cromoglicate, nedocromil, montelukast or zafirlukast.

CS, corticosteroid (unspecified formula); ICS, inhaled corticosteroid; LABA, long-acting $\beta$ agonist; OCS, oral corticosteroid; SABA, short-acting $\beta$ agonist.

the multiple comparisons in our study, ORs with highly significant $p$ values $(p<0.01)$ should be considered most likely to be real effects not due to chance. Only the association of musculoskeletal malformation with cromone medications had a $p$ value smaller than this $(p=0.002)$; however, cromone exposure was still extremely rare and thus statistical power was low, so this result should be interpreted with caution. Furthermore, there was no consistent pattern in specific types of malformation associated with the exposure. Exposure to newer leucotriene receptor antagonists was also rare in this population, which limited a current assessment of their teratogenic safety in pregnancy.

\section{Interpretation in context of previous studies}

Most previous studies have found no relative increase in congenital malformation in children born to mothers with asthma compared with those born to mothers without asthma, ${ }^{28-35}$ which is in keeping with our results of currently active asthma in women. Only three of these studies had adequate statistical power and adjusted for potential confounding factors. ${ }^{28-30}$ A study of approximately 600 children with malformations reported a relative increase of congenital malformation in children born to mothers with asthma ${ }^{36}$ and, although the largest study of over 20000 malformations in Hungary $^{13}$ found a marginal increased risk overall (OR 1.2, 95\% CI 1.0 to 1.3$)$, the only system-specific malformation to reach statistical significance at the $5 \%$ level was club foot, which the authors attribute to more preterm births in women with asthma.

Regarding asthma treatment in pregnancy, in 2000 Jadad $^{12}$ emphasised the need for large observational studies as the only current way to assess the safety of conventional and new asthma medications. However, a 2005 report again raised the lack of sufficient data. ${ }^{17}$ The British Thoracic Society (BTS) continues to grade asthma medications as C or $\mathrm{D},{ }^{6}$ which provide the weakest evidence for safety in pregnancy. The US Food and Drug Administration (FDA) classifies asthma medications as $\mathrm{B}$ or $\mathrm{C},{ }^{37}$ which stipulate that only animal studies have provided evidence against teratogenicity and there are no adequate human data to estimate true risks. Table 4 shows studies that have reported statistical analyses of congenital malformations associated with specific gestational drug exposures in maternal asthma and have used unexposed comparison

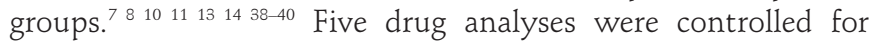
potential confounding factors, ${ }^{7} 10143839$ although only two previous studies ${ }^{13}{ }^{14}$ had adequate statistical power to test the effects of varying asthma medications and only one ${ }^{14}$ could adjust these for potential confounders. In the largest study, Kallen et al found an OR of 1.09 (95\% CI 1.03 to 1.15) for any congenital malformation in offspring associated with maternally-reported exposure to any anti-asthmatic drug reported at initial maternal healthcare visits in pregnancy. They reported small statistically significant increases in severe cardiac defects, orofacial clefts and anal atresia, although they stated these may have been chance findings. They did not present a teratogenic assessment of specific exposure to gestational cromones or to oral corticosteroids, although cromoglicic acid was included in the overall group of anti-asthma drugs. In another case-control study, Tamasi et $a l^{13}$ only found an increased risk of malformation associated with gestational fenoterol exposure (unadjusted OR $1.6,95 \%$ CI 1.3 to 2.0 ) but not with cromones or other specific medications, although they did not assess gestational drug exposures with system-specific malformations. Relative methodological differences to our study include asthma drug exposures that were recorded via postal questionnaires to mothers after the birth of the child in the study by Tamasi et al, probable differential ascertainment of information between mothers of cases and controls, inclusion of minor malformations such as club foot and undescended testis, and an earlier study period (1980-96) resulting in less asthma medication use overall and rare use of newer asthma therapies such as longacting $\beta$ agonists. ${ }^{13}{ }^{15} 16$ In an early 1982 case series, Wilson ${ }^{41}$ reported that, among 296 women exposed to sodium cromoglicate in pregnancy, only $4(1.4 \%)$ of their offspring had congenital malformations which was lower than the $2-3 \%$ 


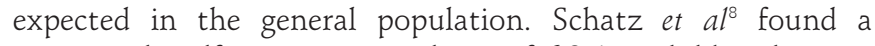
congenital malformation prevalence of $6.2 \%$ in children born to 243 women exposed to cromolyn in pregnancy, which showed no statistically significant difference from the prevalence in unexposed women $(4.9 \%)$, although no multivariate analyses were conducted. Currently, both sodium cromoglicate and nedocromil are assigned to US FDA category B with no evidence of congenital malformations in animal studies, ${ }^{37}$ yet no adequately well-controlled studies have been conducted in pregnant women. The BTS assigns grade $\mathrm{C}$ to cromones and suggests that they be used as normal during pregnancy. ${ }^{6}$

\section{CONCLUSIONS}

Our findings indicate no increase in the risk of major congenital malformation in children born to mothers with currently treated asthma. Management of asthma with medications during pregnancy in accordance with the current guidelines appears to be safe overall. However, older cromones may carry a moderate teratogenic risk and their use in pregnancy should be cautioned.

Funding: This study was funded by a grant from Asthma UK. Asthma UK did not have any role in the design and conduct of the study; collection, management, analysis and interpretation of the data; the preparation, review or approval of the manuscript; or in the decision to submit the paper for publication. No authors work for Asthma UK and all authors are thus independent researchers from the funders.

\section{Competing interests: None.}

Ethics approval: Ethical approval for this study was obtained from the Medical Research Ethics Committee in 2004. All patient records in THIN are anonymised to ensure that researchers cannot identify individuals.

LJT participated in the literature review, development of the study design, data management, data analysis, writing the article and revising article drafts for publication. SAL, PD and LS participated in the development of the study design, interpretation of the data and revising article drafts for publication. TMMcK participated in the interpretation of the data and revising article drafts for publication. CJPS participated in the initial data management and revising article drafts for publication. JEG participated in the data management, interpretation of the data and revising article drafts for publication. RBH (guarantor) had the initial idea for the study and its design and participated in the initial literature review, development of the study design, interpretation of the data and revising article drafts for publication. He had full access to all of the data in the study and takes responsibility for the integrity of the data and the accuracy of the data analysis. All authors have seen and approved the final version.

\section{REFERENCES}

1. Kwon HL, Belanger K, Bracken MB. Asthma prevalence among pregnant and childbearing-aged women in the United States: estimates from national health surveys. Ann Epidemiol 2003;13:317-24.

2. Andrade SE, Gurwitz JH, Davis RL, et al. Prescription drug use in pregnancy. Am J Obstet Gynecol 2004;191:398-407.

3. Petrini J, Damus K, Russell R, et al. Contribution of birth defects to infant mortality in the United States. Teratology 2002;66(Suppl 1):S3-6

4. Cooper N. Analysis of infant mortality risk factors and by cause of death in England and Wales. In: Geographic variations in health. Decennial Supplement DS16. Chapter 7. Published with permission of the Controller of Her Majesty's Stationery Office (HMSO). London: Office for National Statistics, 2002

5. National Institutes of Health (NIH). NAEPP Working Group Report on managing asthma during pregnancy: recommendations for pharmacologic treatment. Updated 2004. Bethesda, MD: Department of Health and Human Services; National Institutes of Health; National Heart, Lung and Blood Institute, March 2005.

6. British Thoracic Society/Scottish Intercollegiate Guidelines Network. British guideline on the management of asthma: a national clinical guideline. Revised edition. 2008. http://www.brit-thoracic.org.uk/Clinicallnformation/Asthma/AsthmaGuidelines/ tabid/83/Default.aspx (accessed 2 September 2008).

7. Schatz M, Zeiger RS, Harden KM, et al. The safety of inhaled beta-agonist bronchodilators during pregnancy. J Allergy Clin Immunol 1988;82:686-95.
8. Schatz M, Zeiger RS, Harden K, et al. The safety of asthma and allergy medications during pregnancy. J Allergy Clin Immunol 1997;100:301-6.

9. Kallen B, Rydhstroem $H$, Aberg A. Congenital malformations after the use of inhaled budesonide in early pregnancy. Obstet Gynecol 1999:93:392-5.

10. Alexander S, Dodds L, Armson BA. Perinatal outcomes in women with asthma during pregnancy. Obstet Gynecol 1998;92:435-40.

11. Stenius-Aarniala B, Riikonen S, Teramo K. Slow-release theophylline in pregnant asthmatics. Chest 1995;107:642-7.

12. Jadad AR, Sigouin C, Mohide PT, et al. Risk of congenital malformations associated with treatment of asthma during early pregnancy. Lancet 2000;355:119.

13. Tamasi L, Somoskovi A, Muller V, et al. A population-based case-control study on the effect of bronchial asthma during pregnancy for congenital abnormalities of the offspring. J Asthma 2006;43:81-6.

14. Kallen B, Otterblad Olausson P. Use of anti-asthmatic drugs during pregnancy. 3. Congenital malformations in the infants. Eur J Clin Pharmacol 2007:63:383-8.

15. Czeizel AE, Petik D, Vargha P. Validation studies of drug exposures in pregnant women. Pharmacoepidemiol Drug Saf 2003;12:409-16.

16. Czeizel AE. The role of pharmacoepidemiology in pharmacovigilance: rational drug use in pregnancy. Pharmacoepidemiol Drug Saf 1999;8(Suppl 1):S55-61.

17. Demoly P, Daures JP. Managing asthma during pregnancy. Lancet 2005:365:1212-3

18. Lewis JD, Schinnar R, Bilker WB, et al. Validation studies of the health improvement network (THIN) database for pharmacoepidemiology research. Pharmacoepidemiol Drug Saf 2007;16:393-401.

19. Bourke A, Dattani H, Robinson M. Feasibility study and methodology to create a quality-evaluated database of primary care data. Inform Prim Care 2004:12:171-7.

20. Tata L, Hubbard R, McKeever T, et al. Fertility rates in women with asthma, eczema, and hay fever: a general population-based cohort study. Am J Epidemiol 2007:165:1023-30.

21. EUROCAT. European Surveillance of Congenital Anomalies. Malformation coding guides. http://www.eurocat.ulster.ac.uk/pubdata/Publications.html.

22. Morris R, Carstairs V. Which deprivation? A comparison of selected deprivation indexes. J Public Health Med 1991;13:318-26.

23. Williams RL. A note on robust variance estimation for cluster-correlated data. Biometrics 2000;56:645-6.

24. EUROCAT. European Surveillance of Congenital Anomalies. Prevalence data 19882004. http://www.bio-medical.co.uk/eurocatlive/search.cgi (accessed October 2006).

25. Hansell A, Hollowell J, Nichols T, et al. Use of the General Practice Research Database (GPRD) for respiratory epidemiology: a comparison with the 4th Morbidity Survey in General Practice (MSGP4). Thorax 1999;54:413-9.

26. Howard LM, Goss C, Leese M, et al. Medical outcome of pregnancy in women with psychotic disorders and their infants in the first year after birth. Br J Psychiatry 2003;182:63-7.

27. Hoare J, Bruce M, Majeed A. Prevalence of treated asthma and its management in general practice in England and Wales, 1994-1998. Health Statistics Quarterly Volume 17, Spring 2003

28. Kallen B, Rydhstroem H, Aberg A. Asthma during pregnancy: a population based study. Eur J Epidemiol 2000;16:167-71.

29. Enriquez R, Griffin MR, Carroll KN, et al. Effect of maternal asthma and asthma control on pregnancy and perinatal outcomes. J Allergy Clin Immunol 2007:120:625-30.

30. Liu S, Wen SW, Demissie K, et al. Maternal asthma and pregnancy outcomes: a retrospective cohort study. Am J Obstet Gynecol 2001;184:90-6.

31. Sobande AA, Archibong El, Akinola SE. Pregnancy outcome in asthmatic patients from high altitudes. Int J Gynaecol Obstet 2002;77:117-21.

32. Stenius-Aarniala B, Piirila P, Teramo K. Asthma and pregnancy: a prospective study of 198 pregnancies. Thorax 1988;43:12-8.

33. Stenius-Aarniala BS, Hedman J, Teramo KA. Acute asthma during pregnancy. Thorax 1996:51:411-4.

34. Schatz M, Zeiger RS, Hoffman CP, et al. Perinatal outcomes in the pregnancies of asthmatic women: a prospective controlled analysis. Am J Respir Crit Care Med 1995:151:1170-4.

35. Dombrowski MP, Schatz M, Wise R, et al. Asthma during pregnancy. Obstet Gynecol 2004;103:5-12

36. Demissie $\mathbf{K}$, Breckenridge MB, Rhoads GG. Infant and maternal outcomes in the pregnancies of asthmatic women. Am J Respir Crit Care Med 1998;158:1091-5.

37. Liccardi G, Cazzola M, Canonica GW, et al. General strategy for the management of bronchial asthma in pregnancy. Respir Med 2003;97:778-89.

38. Bakhireva LN, Jones KL, Schatz M, et al. Safety of leukotriene receptor antagonists in pregnancy. J Allergy Clin Immunol 2007;119:618-25.

39. Blais L, Beauchesne MF, Rey E, et al. Use of inhaled corticosteroids during the first trimester of pregnancy and the risk of congenital malformations among women with asthma. Thorax 2007;62:320-8.

40. Schatz M, Dombrowski MP, Wise R, et al. The relationship of asthma medication use to perinatal outcomes. J Allergy Clin Immunol 2004:113:1040-5.

41. Wilson J. Utilisation du chromoglycate de sodium au cours de la grossesse. [Disodium cromoglicate use during pregnancy]. Acta Ther 1982:8:45-51. 